\title{
(2) OPEN ACCESS \\ Research priorities for mental health in schools in the wake of COVID-19
}

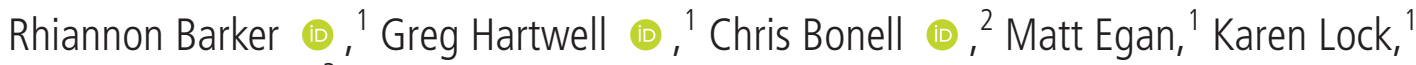 \\ Russell M Viner (i) ${ }^{3}$
}

${ }^{1}$ SPHR, London School of Hygiene \& Tropical Medicine, London, UK

${ }^{2}$ PHES, London School of Hygiene \& Tropical Medicine, London, UK

${ }^{3}$ Institute of Child Health, University College London, London, UK

Correspondence to Dr Rhiannon Barker, SPHR, London School of Hygiene \& Tropical Medicine, London WC1E 7HT, UK:

rhiannon.barker@Ishtm.ac.uk

Received 13 August 2021 Accepted 8 November 2021

Check for updates

(C) Author(s) (or their employer(s)) 2021. Re-use permitted under CC BY-NC. No commercial re-use. See rights and permissions. Published by BMJ.

To cite: Barker R, Hartwell G, Bonell C, et al. J Epidemiol

Community Health Epub

ahead of print: [please

include Day Month Year].

doi:10.1136/jech-2021-

217902

\begin{abstract}
Children and young people (CYP) have suffered challenges to their mental health as a result of the COVID-19 pandemic; effects have been most pronounced on those already disadvantaged. Adopting

a whole-school approach embracing changes to school environments, cultures and curricula is key to recovery, combining social and emotional skill building, mental health support and interventions to promote commitment and belonging. An evidence-based response must be put in place to support schools, which acknowledges that the mental health and well-being of CYP should not be forfeited in the drive to address the attainment gap. Schools provide an ideal setting for universal screening of mental well-being to help monitor and respond to the challenges facing CYP in the wake of the pandemic. Research is needed to support identification and implementation of suitable screening methods.
\end{abstract}

COVID-19 has had significant impacts on the physical and mental well-being of children and young people (CYP) around the world. ${ }^{1}$ Schools provide essential structure, routine and support for many students, particularly the most vulnerable. Growing evidence suggests a strong link between mental health and academic attainment ${ }^{2}$; a recent English study suggests mental health at ages 11-14 predicts attainment at age $16 .^{3}$ This relationship is likely bidirectional, with data suggesting that exam anxiety is more significant in those who perceive their academic ability as low. ${ }^{4}$ Additionally, analysis from a large longitudinal cohort of parents and children in Bristol, UK, indicates that low attainment at 16 predicts increased depressive symptoms at age $18 .^{5}$

The pandemic has presented enormous challenges, creating crises in both academic attainment and CYP's mental health. As education sectors worldwide try to return to normality following periods of lockdown, there are dual imperatives: to provide effective support to address student mental health and well-being, while also addressing gaps and inequalities in academic progress. We argue that, following the upheaval of the pandemic, schools must be supported to address the mental health and well-being of both students and staff. This can be most effectively achieved via delivery of whole-school initiatives and promotion of positive whole-school culture by school leaders. Specifically, we highlight the importance of routine screening of student well-being in schools, and outline evidence demonstrating that both mental health and attainment can be addressed through a range of interventions relating to school culture including social and emotional learning, school mental health provision and work to promote a sense of commitment and belonging.

\section{THE IMPACT OF COVID-19 ON CYP'S MENTAL HEALTH}

Approximately half of adult mental health disorders begin during adolescence. ${ }^{6}$ International evidence indicates that CYP's mental health was already deteriorating before pandemic, with increasing proportions of teenagers experiencing symptoms of distress or anxiety, or engaging in self-harm. ${ }^{7}$ This is concerning given that poor mental health in these age groups is associated with adverse socioeconomic and mental health outcomes in later life. Results from a meta-analysis show that adolescents who suffer depression are $76 \%$ more likely to fail to complete secondary school and $66 \%$ more likely to be unemployed. ${ }^{8}$ The burden is furthermore socially patterned, with socioeconomically disadvantaged CYP more likely to experience mental health problems and self-harm, ${ }^{9}{ }^{10}$ while being less likely to receive referrals into mental health services. ${ }^{9}$

The long periods of isolation and uncertainty that the pandemic has forced on CYP have generated additional challenges. Systematic reviews examining impacts of school closures conclude that they have significantly harmed health and well-being in CYP. ${ }^{11}$ The isolation and upheaval created by closures are most likely to have impacted adversely on CYP from lower socioeconomic groups for whom school can be a crucial source of support. ${ }^{12}$ Adolescents from black, Asian and minority ethnic (BAME) groups show similar patterns to the adult BAME population, for whom pre-existing inequities have been exacerbated. ${ }^{3} 13$

The pandemic's impact is however not uniform; some studies note a protective effect with certain students reporting mental health benefits from reduced school-based academic pressures and more relaxed timetables. ${ }^{14}$ A systematic review ${ }^{15}$ examining COVID-19's impact on adolescent mental health identifies several protective factors such as awareness of transmission routes, good parent-child relationships and strong family structure. It appears that those children receiving less stability and support from their home environment are at heightened risk. Commentators have also conjectured that the ability to stay in touch with peers, through good internet availability and access to social media, may have helped guard against loneliness and isolation. ${ }^{14}$ 


\section{PROMISING INTERVENTIONS FOR THE SCHOOL SECTOR'S RECOVERY}

Work to build support for improving the mental health of CYP in schools needs to learn from the range of promising interventions that have been shown to be effective in improving measures of student well-being. In particular, many successful behavioural interventions have focused on developing social and emotional competencies which can positively impact on student mental health and academic and behavioural development. ${ }^{16}$

Yet challenges have been highlighted around the implementation and embedding of classroom-based interventions to improve health and well-being. ${ }^{17}$ Notably, there have been tendencies to overlook the specific context of the school or failure to consider the wider system that may create barriers. ${ }^{18}$ Emphasis has now turned from the adoption of programmes targeting health-related behaviours to more comprehensive system-wide approaches. The focus on a whole-school approach to positive mental health is particularly urgent following the almost ubiquitous rise in need during the pandemic and the imperative to provide more generic well-being awareness. Practitioners are looking beyond classroom-based initiatives to interventions that impact on the 'whole-school', such as the Learning Together Programme, ${ }^{19}$ focusing on reducing school-based bullying and aggression, and improving mental health. While the need for more rigorous evidence has been highlighted, an association is apparent between the school-level environment and mental health. ${ }^{20}$ In addition, several studies have reported positive impacts of whole-school interventions on student well-being and mental health. ${ }^{20}{ }^{21}$ Systematic reviews have also considered whole-school approaches to tackling health-related behaviours. ${ }^{22-24}$ Despite methodological challenges, these show promising findings linking school ethos and culture to positive mental health outcomes.

Central to a clear understanding of student outcomes is an insight into the mechanisms responsible for CYP engagement, the impact of school culture and the way students negotiate social networks. Greater clarity regarding how change is brought about will support the building of social and emotional skills, shown to be protective against behaviours which impact negatively on mental health. ${ }^{17}$ This may help, for instance, with growing anxieties around the areas of harmful social media use, image sharing and sexual harassment, as highlighted by Ofsted's recent report. ${ }^{25}$ Work to foster positive school culture can aim to denormalise such harmful behaviours.

School environments are complex and the way a school impacts on those who study or work within it is influenced by a wide range of causal mechanisms, all of which need to be considered in a whole-school strategy. The Anna Freud Centre sets out a strategic framework for achieving improved mental health and well-being in schools: strong leadership promoting a supportive culture; working together at all levels (staff, students, parents and wider communities); understanding need through routine measurement and monitoring; promoting well-being through a range of whole-school initiatives and interventions; and supporting staff with their own well-being. ${ }^{26}$

\section{MOVING FORWARD}

The temptation to adopt practices which react to immediate crises rather than to invest in longer term support based on best evidence must be avoided. Positive results emerging from wholeschool interventions ${ }^{22} 2728$ can guide future work to strengthen school culture and point towards the particular importance of aspects such as student/teacher relationships, bullying reduction and student participation and engagement. The danger is that pressures on schools to focus on academic attainment and 'curriculum catch-up' will over-ride the need to address student well-being and mental health. This may in turn adversely impact those aspects of school culture which have been shown to have protective effects on mental health, such as the participation of CYP in school governance. Crucially, a system-wide commitment to the teaching of social and emotional skills and the provision of mental health support is required, as well as interventions to promote commitment and belonging. ${ }^{27}$ Together, these have the potential not just to improve student mental health, but to increase attainment and lead to healthier, happier adult lives. Positive correlations found between good mental health and improved academic outputs ${ }^{23}$ add further support to the importance of working, synergistically, on both these goals.

Leadership strategies that recognise the importance of staff and student mental health in COVID-19 recovery will be key. These should recognise the inequalities that have been exacerbated by lockdowns, improve schools' physical environments, foster staff/student relationships and address bullying. Evidence from studies of school mental health initiatives is relevant here, given they suggest the effects of interventions are higher when targeting higher risk children. ${ }^{29}$ Parallel to this is the need for adequate regulatory leverage, delivered through organisations such as Ofsted, to continue to support and incentivise mental health promotion in schools.

While schools collect multiple data relating to attainment, standardised information on the mental health and well-being of their students is rarely collected. Yet commentators suggest that, given their universality and extensive engagement with CYP, schools provide ideal settings for identifying those at risk of developing mental health difficulties. We recommend, that to monitor rising mental health challenges in our schools, a more standardised system of screening be implemented backed by increased research funding to explore and guide how to make best use of existing resources. All proposals should acknowledge the existing pressures on staff time and school resource, focusing on identifying a viable and pragmatic working model.

Within these future plans, a range of complex factors need to be considered including: an agreed definition of mental health (holistic well-being vs absence of clinical symptoms); reliability and validity of selected tools; design and implementation of screening (including staff training); cultural appropriateness and diversity; and costs and benefits. ${ }^{30}$ Processes to seek informed consent from students and parents should be established, while recognition is needed that screening for mental health issues should be backed by the resources to enable appropriate responses to identified need. Intense pressures on finite resources require that, once need is identified, the most appropriate 'response route' is followed. The establishing of Mental Health Support Teams, ${ }^{31}$ intended to provide extra capacity to deliver evidencebased interventions in schools and create better links to existing services, is an encouraging step. However, research is needed to monitor how support is delivered and to test new approaches such as the colocation of mental health staff in schools.

We propose that the complexity of school-based mental health research benefits from the guidance of a conceptual framework which acknowledges the interaction and influence of a wide range of factors at all system levels. The Systems View of School Climate ${ }^{32}$ framework is one such model which adopts a system perspective and demonstrates the importance, both of factors within the school microsystem such as beliefs, values and relationships, as well as more distal ones in the mesosystem and macrosystem, which can all contribute towards creating 
an environment that works to build positive mental health in students and staff.

Finally, the importance of identifying interventions which address priorities articulated by CYP should not be overlooked, with students themselves involved in this work. Enabling this may require the development of new measures which consider concepts of 'positive mental health' and 'flourishing'. Useful results should begin to emerge, for instance, from ongoing innovative projects ${ }^{33}$ where students are collaborating as 'active co-researchers' using participatory approaches to measure wellbeing and respond to the rising mental health challenges faced by CYP.

Twitter Rhiannon Barker @BarkingMc and Russell M Viner @russellviner

Contributors RB wrote the initial article which was scoped during the initial phase of work for an NIHR-funded Public Mental Health Programme. The draft was commented on by $\mathrm{GH}, \mathrm{CB}, \mathrm{ME}, \mathrm{KL}$ and RMV.

Funding This article was compiled as part of a scoping study undertaken within the National Institute for Health Research (NIHR) School for Public Health Research (SPHR)-funded Public Mental Health Programme (grant reference: SPHR-PROGPMH-WP6.1\&6.2). NIHR SPHR is a partnership between the Universities of Sheffield; Bristol; Cambridge; Imperial; and the University College London; the London School of Hygiene \& Tropical Medicine (LSHTM); LiLaC-a collaboration between the Universities of Liverpool and Lancaster; and Fuse-the Centre for Translational Research in Public Health, a collaboration between Newcastle, Durham Northumbria, Sunderland and Teesside Universities.

Disclaimer The funders had no role in the design of the study, or collection, analysis and interpretation of the data, or in the decision to publish, or in writing the manuscript.

\section{Competing interests None declared.}

Patient consent for publication Not required.

Provenance and peer review Not commissioned; externally peer reviewed.

Open access This is an open access article distributed in accordance with the Creative Commons Attribution Non Commercial (CC BY-NC 4.0) license, which permits others to distribute, remix, adapt, build upon this work non-commercially, and license their derivative works on different terms, provided the original work is properly cited, appropriate credit is given, any changes made indicated, and the use is non-commercial. See: http://creativecommons.org/licenses/by-nc/4.0/.

\section{ORCID iDs}

Rhiannon Barker http://orcid.org/0000-0001-7854-6810

Greg Hartwell http://orcid.org/0000-0001-9153-7126

Chris Bonell http://orcid.org/0000-0002-6253-6498

Russell M Viner http://orcid.org/0000-0003-3047-2247

\section{REFERENCES}

1 Loades ME, Chatburn E, Higson-Sweeney N, et al. Rapid systematic review: the impact of social isolation and loneliness on the mental health of children and adolescents in the context of COVID-19. J Am Acad Child Adolesc Psychiatry 2020;59:1218-39.

2 Lereya ST, Patel M, Dos Santos JPGA, et al. Mental health difficulties, attainment and attendance: a cross-sectional study. Eur Child Adolesc Psychiatry 2019;28:1147-52.

3 Smith NR, Marshall L, Albakri M. 3 The impact of mental health and wellbeing on GCSE performance in England: a longitudinal analysis of the National pupil database linked to understanding Society. BMJ Paediatrics Open;3.

4 Howard E. A review of the literature concerning anxiety for educational assessments. Research and analysis, Coventry, UK: Ofqual, 2020.

5 López-López JA, Kwong ASF, Washbrook E, et al. Trajectories of depressive symptoms and adult educational and employment outcomes. BJPsych Open 2020;6.

6 Kessler RC, Berglund P, Demler O, et al. Lifetime prevalence and age-of-onset distributions of DSM-IV disorders in the National comorbidity survey replication. Arch Gen Psychiatry 2005;62:593-602.

7 Collishaw S. Annual research review: secular trends in child and adolescent mental health. J Child Psychol Psychiatry 2015;56:370-93.
8 Clayborne ZM, Varin M, Colman I. Systematic review and meta-analysis: adolescent depression and long-term psychosocial outcomes. J Am Acad Child Adolesc Psychiatry 2019;58:72-9

9 Morgan C, Webb RT, Carr MJ, et al. Incidence, clinical management, and mortality risk following self harm among children and adolescents: cohort study in primary care. BMJ 2017:359:j4351.

10 Reiss F. Socioeconomic inequalities and mental health problems in children and adolescents: a systematic review. Soc Sci Med 2013:90:24-31.

11 Viner RM, Russell S, Saulle R. Impacts of school closures on physical and mental health of children and young people: a systematic review. MedRxiv 2021.

12 Ford T, John A, Gunnell D. Mental health of children and young people during pandemic. BMJ 2021;372:n614.

13 Campbell D. Covid-19 affects BAME youth mental health more than white peers study, 2021. The Guardian. Available: http://www.theguardian.com/society/2020/jun/ 21/covid-19-hits-bame-youth-mental-health-worse-than-white-peers-study [Accessed 15 Apr 2021].

14 Widnall E, Winstone L, Mars B. Young people's mental health during the COVID-19 pandemic: Initial findings from a secondary school survey study in South West England. National Institute for Health Research School for Public Health Research, 2020

15 Octavius GS, Silviani FR, Lesmandjaja A, et al. Impact of COVID-19 on adolescents' mental health: a systematic review. Middle East Current Psychiatry 2020;27:72.

16 Durlak JA, Weissberg RP, Dymnicki AB, et al. The impact of enhancing students' social and emotional learning: a meta-analysis of school-based universal interventions. Child Dev 2011;82:405-32.

17 Barry MM, Clarke AM, Dowling K. Promoting social and emotional well-being in schools. Health Educ 2017;117:434-51.

18 Caldwell DM, Davies SR, Hetrick SE, et al. School-based interventions to prevent anxiety and depression in children and young people: a systematic review and network meta-analysis. Lancet Psychiatry 2019;6:1011-20.

19 UCL. Learning together. UCL Great Ormond Street Institute of Child health, 2019. Available: https://www.ucl.ac.uk/child-health/research/population-policy-and-practiceresearch-and-teaching-department/champp/learning-together [Accessed 9 Apr 2021].

20 O'Reilly M, Svirydzenka N, Adams S, et al. Review of mental health promotion interventions in schools. Soc Psychiatry Psychiatr Epidemiol 2018:53:647-62.

21 Bonell $C$, Allen E, Warren E, et al. Effects of the learning together intervention on bullying and aggression in English secondary schools (inclusive): a cluster randomised controlled trial. Lancet 2018;392:2452-64.

22 Lister-Sharp D, Chapman S, Stewart-Brown S, et al. Health promoting schools and health promotion in schools: two systematic reviews. Health Technol Assess 1999:3:1-207.

23 MacArthur G, Caldwell DM, Redmore J, et al. Individual-, family-, and school-leve interventions targeting multiple risk behaviours in young people. Cochrane Database Syst Rev 2018;10:CD009927.

24 Langford R, Bonell C, Jones H, et al. The World Health Organization's health promoting schools framework: a Cochrane systematic review and meta-analysis. BMC Public Health 2015;15:130.

25 Ofsted. Review of sexual abuse in schools and colleges. Research and analysis, Gov. UK, 2021. Available: https://www.gov.uk/government/publications/review-of-sexualabuse-in-schools-and-colleges/review-of-sexual-abuse-in-schools-and-colleges. 10 [Accessed 9 Nov 2021].

26 Wolpert M, Harris R, Hodges S. THRIVE framework for system change. Anna Freud Centre, 2019. Available: https://www.annafreud.org/media/9254/thrive-frameworkfor-system-change-2019.pdf [Accessed 20 Jul 2021].

27 Bonell C, Allen E, Warren E, et al. A multi-component school environment intervention reduces bullying and risky behaviour and improves mental health and quality of life: findings from the inclusive cluster randomized controlled trial. J Adolesc Health 2018;62:59.

28 Fletcher A, Bonell C, Hargreaves J. School effects on young people's drug use: a systematic review of intervention and observational studies. $J$ Adolesc Health 2008;42:209-20

29 Weare K, Nind M. Mental health promotion and problem prevention in schools: what does the evidence say? Health Promot Int 2011:26(Suppl 1):i29-69.

30 Humphrey N, Wigelsworth M. Making the case for universal school-based mental health screening. Emotion Behav Difficulties 2016;21:22-42.

31 NHS.UK. Mental health support in schools and colleges and faster access to NHS care, 2021. Available: https://www.england.nhs.uk/mental-health/cyp/trailblazers/\#_ Mental Health Support [Accessed 9 Nov 2021].

32 Rudasill KM, Snyder KE, Levinson H, et al. Systems view of school climate: a theoretical framework for research. Educ Psychol Rev 2018:30:35-60.

33 Jessiman T, Kidger J, Limmer M. School culture and student mental health: a participatory action research study, 2020. Available: https://sphr.nihr.ac.uk/research/ school-culture-and-student-mental-health-a-participatory-action-research-study/ [Accessed 22 Oct 2021]. 